\title{
Genotyping and Severity of Rotavirus Infection among Infants and Children with Acute Diarrhea
}

\author{
Manar Fathy ${ }^{1}$, Rania m Amer ${ }^{2,}$ Mohamed A Almalky*1, Sherif El Gebaly ${ }^{1}$ \\ Departments of ${ }^{1}$ Pediatrics and ${ }^{2}$ Microbiology and Immunology, Faculty of Medicine, Zagazig University \\ *Corresponding author: Mohamed A Almalky, Mobile: (+20) 01144444929, E-Mail: drmohamedalmalkyped@ yahoo. com
}

\begin{abstract}
Introduction: Rotavirus (RV) belongs to the Reoviridae virus family and the virion comprises of three concentric protein layers. Worldwide, rotavirus (RV) is the most common cause of severe gastroenteritis (G.E.) among infants and young children especially in those countries which has not launched a RV vaccination program and approximately $40 \%$ of hospitalized patients suffering from gastroenteritis were infected with RV. Objective: To determine the prevalence of rotavirus infections, genotypes and degree of severity of its acute diarrhea in infants and children attending the children hospital, at Zagazig University Hospitals. Patients and methods: this study was done on 140 patients admitted to Children Hospital, Zagazig University suffering of gastroenteritis, Vesikari clinical severity score was done and stool sample was taken from patients, which was tested for RV by dipstick method and positive patients underwent genotyping by immunochromatography using PCR technique.

Results: Among the studied group 128 patients (91.4\%) showed positive results for rotavirus detection by dipstick analysis of stool, while only 12 patients $(8.6 \%)$ were negative. The Vesikari score of severity ranged from 9 to 15 with median of 12 and its mean \pm SD was $11.9 \pm 1.3$. G3 and P8 were the most types in the examined patients.

Conclusion: rotavirus is still the main cause of severe gastroenteritis that requires hospital admission. G3 and P8 are the most detectable genotypes.

Keywords: Diarrhea, Genotyping, Infants and Children, Rotavirus.
\end{abstract}

\section{INTRODUCTION}

Worldwide, rotavirus (RV) is the most common cause of severe gastroenteritis among infants and young children especially in those countries which has not launched a RV vaccination program ${ }^{(1)}$. Every child encounters at least one episode of RV gastroenteritis by the age of 5 years. Each year, about 2 million subjects have to be hospitalized for developing severe RV gastroenteritis while about 25 million patients seek medical help by visiting a physician's office or clinic and 111 million cases require care at home ${ }^{(2)}$. While diarrhea is the second most common cause of fatal childhood illness, about 1.34 million deaths occur worldwide among children aged less than 5 years due to $\mathrm{RV}^{(3)}$.

Though the incidence of RV infection among children in developed and developing countries is similar, outcomes vary widely with $82 \%$ of fatalities estimated to occur in developing countries. Most death occurs in low- and middle-income countries, such as Egypt ${ }^{(4)}$. RV can be detected in high concentrations in the stool of children suffering from gastroenteritis. Control measures such as improved sanitation is not effective in preventing this disease ${ }^{(5)}$.

Several studies performed in the Middle East showed that approximately $40 \%$ of hospitalized patients suffering from gastroenteritis were infected with RV ${ }^{(2,}$ ${ }^{6}$. Rotavirus (RV) belongs to the Reoviridae virus family and the virion comprises of three concentric protein layers ${ }^{(7)}$. The outer capsid consists of two proteins, VP7 and VP4 that are used to classify rotavirus strains into $\mathrm{G}$ (glycoprotein) and $\mathrm{P}$ (protease sensitive) genotypes, respectively ${ }^{(8)}$. Of the $12 \mathrm{G}$ and 15 genotypes known to infect humans, genotypes G1P81, G2P14, G3P8, G4P8 and G9P8 cause over 90\% of rotavirus disease worldwide ${ }^{(9)}$.

The aim of this work was to determine the prevalence of rotavirus infections, genotypes and degree of severity of its acute diarrhea in infants and children attending the Children Hospital, at Zagazig University Hospitals.

\section{SUBJECTS, MATERIALS AND METHODS}

This study was a cross-sectional study conducted in Pediatric Department, Zagazig University Hospitals, Medical Microbiology and Immunology Department and in Medical Scientific and Research Centre, Faculty of Medicine, Zagazig University Hospitals.

For one year surveillance, the data and the stool samples were gathered from January 2019 to January 2020 (in November, December, January months which was the peak of RV). A total of 140 stool specimens were collected from admitted patients diagnosed with acute diarrhea in Pediatric Department, Zagazig University Hospitals. The stool samples were from the consecutive patients in this study period. Case enrollment was done on the basis of inclusion and exclusion criteria. 


\section{Ethical approval:}

An approval of the study was obtained from Zagazig University academic and ethical committee. Informed consent was obtained from written informed consent was taken from parents for participation in the study. After being informed about the aims and process of the study as well as applicable objectives.

Inclusion criteria: Infants and children aged from one month to five years presented with gastroenteritis or acute diarrhea who were not vaccinated with rotavirus vaccine (non-compulsory vaccine in Egypt).

Exclusion criteria: Children with chronic and/or persistent diarrhea, which was defined as diarrhea that lasted for more than two weeks.

All study subjects underwent: Thorough history taking including personal history (age, sex, name, number of children, education and occupation of the parents) and present history (symptoms, duration of symptoms, temperature of the child, hydration state). Physical examination and laboratory investigations including: $\mathrm{Ag}$ detection of rotavirus by immunochromatography and genotyping (for $\mathrm{Ag}$ positive samples) by PCR technique.

Physical examination: for detection of severity of diarrheal disorder using Vesikari score of severity as in table 1 where Mild cases < 7, Moderate cases 7- 10, Severe cases 11- $20^{(\mathbf{1 0})}$.

Table (1): Vesikari score of G.E. severity

\begin{tabular}{|l|c|c|c|}
\hline Parameter & 1 & 2 & 3 \\
\hline $\begin{array}{l}\text { Diarrhea } \\
\text { Maximum } \\
\text { number of stool } \\
\text { per day }\end{array}$ & $1-3$ & $4-5$ & $\geq 6$ \\
\hline $\begin{array}{l}\text { Diarrheal } \\
\text { duration (days) }\end{array}$ & $1-4$ & 5 & $\geq 6$ \\
\hline Vomiting & & & $\geq 5$ \\
\hline $\begin{array}{l}\text { Maximum } \\
\text { number } \\
\text { vomiting of } \\
\text { episodes per } \\
\text { day }\end{array}$ & 1 & $2-4$ & $\geq 3$ \\
\hline $\begin{array}{l}\text { Vomiting } \\
\text { duration (days) }\end{array}$ & 1 & 2 & $\geq 39$ \\
\hline Temperature & $<38.5$ & $38.5-38.9$ & $\geq 6 \%$ \\
\hline Dehydration & N/A & $1-5 \%$ & Hospitalization \\
\hline Treatment & N/A & Rehydration & \\
\hline
\end{tabular}

- Stool samples collection: Stool samples were collected as watery diarrhea in sterile containers. On reaching the lab each sample was divided into two Falcon tubes (15 $\mathrm{ml}$ ) (one frozen at $-20^{\circ} \mathrm{C}$ for immunochromatography test and the other at $-80^{\circ} \mathrm{C}$ for PCR genotyping).
- Rotavirus antigen detection by RIDA® QUICK Rotavirus (dipsticks) kit: For in vitro diagnostic use. This test is a quick immunochromatographic test for the qualitative determination of rotaviruses in stool samples (Art. No.: N0902, Germany). Procedures and interpretation of results were done according to the manual instructions.

- Samples positive for rotavirus Ag by immunochromatographic test underwent RNA extraction and PCR genotyping.

- Viral RNA extraction by QIAamp ${ }^{\circledR}$ viral RNA minikit (Qiagen); (Extraction kit for viral RNA) (Cat. No. 52904, The Netherlands). Procedures were done according to the manual instructions.

- Rotavirus genotyping: Reagents and materials needed:

a $\quad$ Qiagen ${ }^{\circledR}$ onestep RT-PCR kit (Cat. No.: 210210, The Netherlands).

a Primers

(9con1,9con2,9T1,9T2,9T3P,9T4,9T9B,con3,con2 ,1T1,2T1,3T1,4T1,5T1,ND2)

- Taq DNA polymerase $250 \mu, 10 x$ PCR buffer (HVD Egypt).

a Deionized water.

- For genotyping of rotavirus 2 types of genotyping were done (genotyping for $\mathrm{P}$ proteins ( $\mathrm{P}$ genotyping) and genotyping for $G$ proteins ( $G$ genotyping). (According to the WHO protocol). The protocol for genotyping was provided by the WHO Rotavirus Collaborating Center, Atlanta, Georgia, USA and also used by the Eastern Mediterranean Regional Rotavirus Laboratory ${ }^{(\mathbf{1 1})}$.

\section{Statistical analysis}

The collected data were coded, processed and analyzed using the SPSS (Statistical Package for Social Sciences) version 22 for Windows ${ }^{\circledR}$ (IBM SPSS Inc, Chicago, IL, USA). Data were tested for normal distribution using the Shapiro Walk test. Qualitative data were represented as frequencies and relative percentages. Chi square test $(\chi 2)$ to calculate difference between two or more groups of qualitative variables. Quantitative data were expressed as mean \pm SD (Standard deviation). $\mathrm{P}$ value $<0.05$ was considered significant.

\section{RESULTS}

Our sample consisted of (140) patients, 87 male $(62.1 \%)$ and 53 female $(37.9 \%)$ with age ranges from 1 to 50 months (mo). fifty infants from 1 to 12 months represent (35.7\%), 38 infant from 12 to 24 months (27.1\%), 36 children from 24 to 36 mo (25.7\%) and 16 children from 36 to 50 mo (11.4\%). The Vesikari score of severity ranged from 9 to 15 with median of 12 and 
its mean \pm SD was $11.9 \pm 1.3$, with mean duration of diarrhea of $2.8 \pm 0.8$ days and mean duration of vomiting $2.1 \pm 0.6$ days. Diarrheal duration ranged from 1 to 5 days, vomiting continued from 1 to 3 days and hospital stay ranged from 2 to 6 days. $87.1 \%$ of our patients showed severe dehydration while 22.9 had mild dehydration. Among the studied group 128 patients $(91.4 \%)$ showed positive results for rotavirus detection by dipstick analysis of stool, while only 12 patients $(8.6 \%)$ were negative.

There was no statistically significant difference between rota +ve cases and rota -ve cases regarding age, sex, number of motions, duration of diarrhea or vomiting but there was statistically significant difference between them regarding weight, degree of dehydration, Vesikari score and duration of stay in hospital (Tables 2, 3 and 4).

Table (2): Comparing age and sex between positive and negative Rota virus in the studied group

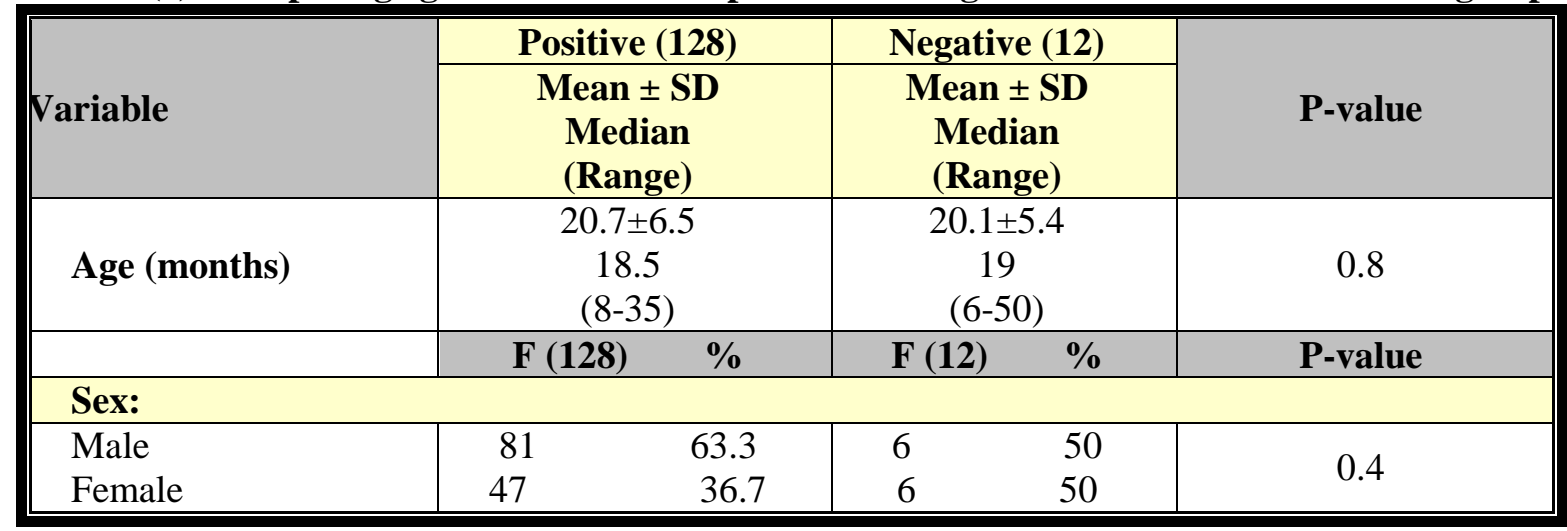

$\mathrm{F}=$ frequency

Table (3): Comparing clinical data between positive and negative rotavirus in the studied group

\begin{tabular}{|c|c|c|c|}
\hline \multirow[b]{2}{*}{ Variable } & Positive (128) & Negative (12) & \multirow[b]{2}{*}{ P-value } \\
\hline & $\begin{array}{c}\text { Mean } \pm \text { SD } \\
\text { Median }\end{array}$ & $\begin{array}{c}\text { Mean } \pm \text { SD } \\
\text { Median }\end{array}$ & \\
\hline Vesikari score of Severity & $\begin{array}{c}13.9 \pm 1.4 \\
13\end{array}$ & $\begin{array}{c}10.7 \pm 0.8 \\
10.5\end{array}$ & $<0.001$ \\
\hline Motion numbers & $\begin{array}{c}5.7 \pm 1.2 \\
6\end{array}$ & $\begin{array}{c}5.2 \pm 0.4 \\
5\end{array}$ & 0.2 \\
\hline Diarrheal duration (days) & $\begin{array}{c}2.8 \pm 0.87 \\
3\end{array}$ & $\begin{array}{c}2.7 \pm 0.45 \\
3\end{array}$ & 0.6 \\
\hline Vomiting duration(days) & $\begin{array}{c}2.1 \pm 0.6 \\
2\end{array}$ & $\begin{array}{c}2.2 \pm 0.4 \\
2\end{array}$ & 0.3 \\
\hline Hospital stay(days) & $\begin{array}{c}3.5 \pm 1.3 \\
3\end{array}$ & $\begin{array}{c}2.5 \pm 0.5 \\
2.5\end{array}$ & 0.01 \\
\hline
\end{tabular}

Table (4): Comparing weight and dehydration degree between positive and negative Rota virus in the studied group

\begin{tabular}{|c|c|c|c|c|c|}
\hline \multirow{2}{*}{ Variable } & \multicolumn{2}{|c|}{ Positive } & \multicolumn{2}{|c|}{ Negative } & \multirow{2}{*}{ P-value } \\
\hline & F (128) & $\%$ & $\mathbf{F}(\mathbf{1 2})$ & $\%$ & \\
\hline \multicolumn{6}{|l|}{ Weight } \\
\hline Normal & 27 & 21.1 & 6 & 50 & \multirow{2}{*}{0.02} \\
\hline Underweight & 101 & 78.9 & 6 & 50 & \\
\hline \multicolumn{6}{|l|}{ Dehydration } \\
\hline Moderate & 18 & 14.1 & 6 & 50.0 & \multirow{2}{*}{$<0.002$} \\
\hline Severe & 110 & 85.9 & 6 & 50.0 & \\
\hline
\end{tabular}

$\mathrm{F}=$ frequency

Of our 140 cases only 16 Rota +ve patients (12.5\%) showed G- typing (Fig. 1) and all of them were of G3 type, while 43 patients (33.6\%) showed P typing (Fig. 2) and also all of them were P8. There was statistically significant difference between G3 and nontypable genotyping in degree of dehydration, weight, Vesikari score of severity, 
diarrheal duration, vomiting duration and numbers. And there was no statistically significant difference in other factors (Tables 5 and 6). There was statistically significant difference between P8 and nontypable strain in degree of dehydration, Vesikari score of severity, vomiting duration and numbers. But not in weight, number of motions, duration of diarrhea or hospital stay (tables 7 and 8).

Table (5): Concordance between dehydration degree and genotyping G3 in the studied group

\begin{tabular}{|c|c|c|c|c|c|}
\hline \multirow{2}{*}{ Dehydration degree } & \multicolumn{2}{|c|}{ G3 } & \multicolumn{2}{|c|}{ Nontypable } & \multirow{2}{*}{ P-value } \\
\hline & & $\%$ & $\mathbf{F}(1$ & $\%$ & \\
\hline Moderate dehydration (18) & 8 & 50 & 10 & 8.9 & \multirow{2}{*}{0.001} \\
\hline Severe dehydration (110) & 8 & 50 & 102 & 91.1 & \\
\hline Normal (27) & 8 & 50 & 19 & 17 & \multirow{2}{*}{$<0.003$} \\
\hline Underweight (101) & 8 & 50 & 93 & 83 & \\
\hline
\end{tabular}

$\mathrm{F}=$ frequency

Table (6): Comparing clinical data between G3 and nontypable genotyping in the studied group

\begin{tabular}{|l|c|c|c|}
\hline \multirow{2}{*}{ Variable } & G3 (16) & Nontypable (112) & \multirow{2}{*}{ P-value } \\
\cline { 2 - 4 } & Mean \pm SD & Mean \pm SD & \\
\hline Veslkari score of Severity & $11 \pm 1.6$ & $12.1 \pm 1.2$ & $<\mathbf{0 . 0 0 2}$ \\
\hline Motion numbers & $5.5 \pm 1.1$ & $5.7 \pm 1.2$ & 0.5 \\
\hline Diarrheal duration (days) & $2 \pm 0.7$ & $3 \pm 0.8$ & $\mathbf{0 . 0 0 1}$ \\
\hline Vomiting duration(days) & $1.5 \pm 0.4$ & $2.1 \pm 0.6$ & $\mathbf{0 . 0 0 1}$ \\
\hline Vomiting numbers & $3 \pm 0.7$ & $3.7 \pm 0.7$ & $<\mathbf{0 . 0 0 1}$ \\
\hline Hospital stay(days) & $3.5 \pm 1.1$ & $3.4 \pm 1.1$ & 0.9 \\
\hline
\end{tabular}

Table (7): Concordance between dehydration degree and P8 strain in the studied group

\begin{tabular}{|c|c|c|c|c|c|}
\hline Dehydration degree & & $\%$ & Non & le $(85)$ & P-value \\
\hline Moderate dehydration (18) & 00 & 0.0 & 18 & 21.2 & \multirow{2}{*}{$<0.001$} \\
\hline Severe dehydration (110) & 43 & 100 & 67 & 78.8 & \\
\hline Normal weight (27) & 12 & 27.9 & 15 & 17.6 & \multirow{2}{*}{0.2} \\
\hline Underweight (101) & 31 & 72.1 & 70 & 82.4 & \\
\hline
\end{tabular}

$\mathrm{F}=$ frequency

Table (8): Comparing clinical data between P8 and nontypable strain in the studied group

\begin{tabular}{|l|c|c|c|}
\hline \multirow{2}{*}{ Variable } & P8 (43) & Nontypable (85) & \multirow{2}{*}{ P-value } \\
\cline { 2 - 3 } & Mean \pm SD & Mean \pm SD & $<0.001$ \\
\hline Vesikari score of Severity & $12.2 \pm 1.1$ & $10.1 \pm 0.9$ & 0.6 \\
\hline Motion numbers & $5.7 \pm 1.3$ & $5.6 \pm 1.1$ & 0.9 \\
\hline Diarrheal duration (days) & $2.8 \pm 0.7$ & $2.9 \pm 0.8$ & $\mathbf{0 . 0 0 1}$ \\
\hline Vomiting duration (days) & $2.4 \pm 0.5$ & $1.8 \pm 0.6$ & $<\mathbf{0 . 0 3}$ \\
\hline Vomiting numbers & $3.8 \pm 0.9$ & $3.5 \pm 0.6$ & 0.9 \\
\hline Hospital stay (days) & $3.5 \pm 1.3$ & $3.4 \pm 1.3$ & \\
\hline
\end{tabular}




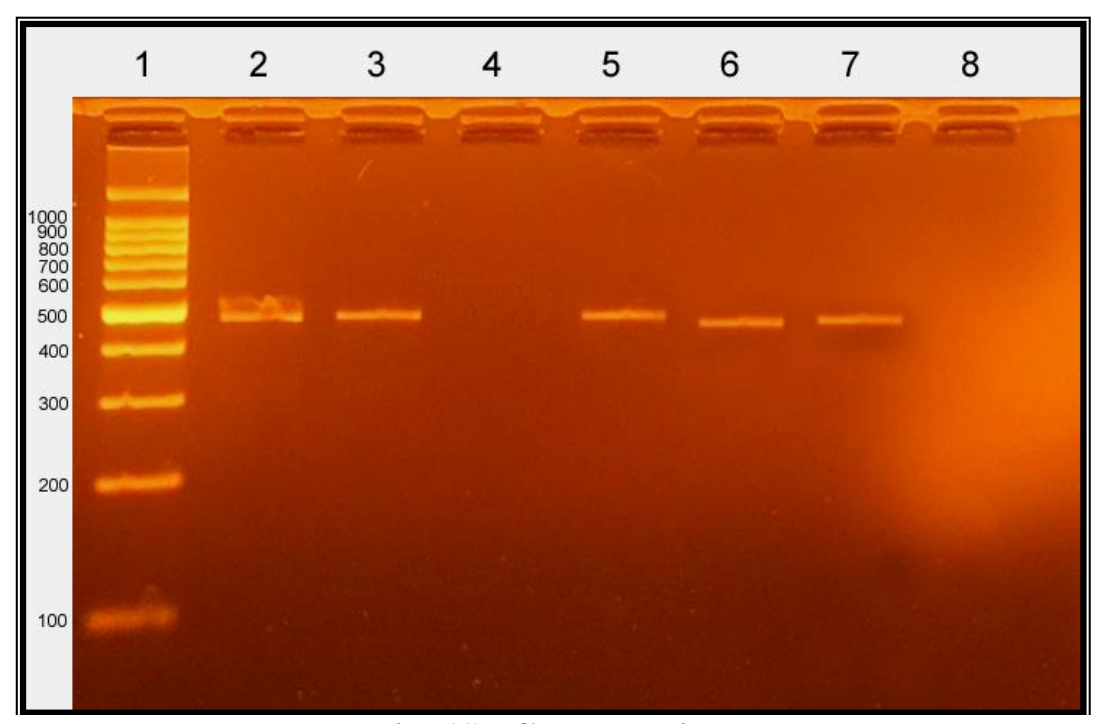

Fig. (1): G genotyping

The gel electrophoresis photo showing:

- In lane 1: The DNA marker (100bp)

- In lanes 2, 3, 5, 6, 7: The bands of $\mathrm{G}$ genotypes with its size (500bp) $\rightarrow \mathrm{G} 3$ genotyping

- But in lane $4,8 \rightarrow$ No genotype bands appear

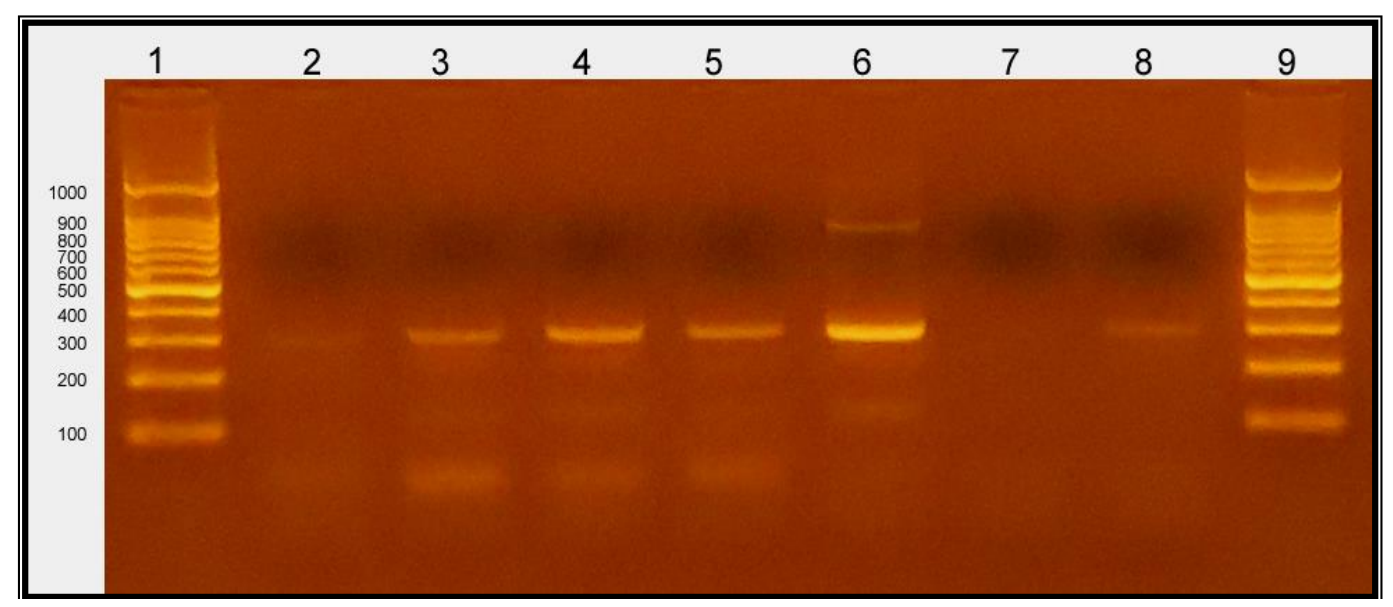

Fig. (2): P genotyping

The gel electrophoresis photo showing:

- In lane 1,9: The DNA marker (100bp)

- In lane 2,3,4 ,5,6,8 : The bands of P genotypes with its size (350bp) $\rightarrow$ P8 genotyping

- But in lane $7 \rightarrow$ No genotype bands appear.

\section{DISCUSSION}

In our study the sample consisted of 140 patients with age range from 6 month to 50 months of them 62.1 were boys and 37.9 were girls. All cases showed moderate to severe diarrheal disorder according to Vesikari scoring system. We found significant difference between moderately and severely dehydrated children regarding their different age group as water represent more of body weight in younger age group, which was in agreement with Trojnar et al. ${ }^{(12)}$ who reported the significant difference in age and weight with dehydrated children and also in agreement with Ahmed et al. ${ }^{(13)}$ who reported that most cases of G.E. were in the first year of life, but this finding was in the contrary to Hegazi et al. ${ }^{(14)}$ who found most cases of rotavirus infection were in the second year of life. This difference may be due to the fact that his study population were vaccinated with rotavirus vaccine.

About $91.4 \%$ of the studied group was positive for rotavirus by dipstick. These data are not near to that published by Ahmed et al. ${ }^{(13)}$ who found that the 
prevalence of rotavirus infection among Egyptian children was $40 \%$. This difference may be related to the different study design; as his study was public or epidemiological prospective study but ours was cross sectional and dealt only with hospitalized children with the severest form of infection, which mainly related to rotavirus rather than to other agents ${ }^{(\mathbf{1 3})}$. There was no significant difference between rotavirus positive and negative cases regarding both age and sex and this is matched with most published data like that published by Ahmed et al. ${ }^{(13)}$, Bulut et al. ${ }^{(15)}$ and Mchaile et al. ${ }^{(16)}$. But in rotavirus positive cases boys were more affected (63.3\%). This was in agreement with Burton et al. ${ }^{(17)}$ who reported that $71.9 \%$ of his study group were males.

We found that the prevalence of rotavirus infection is more during first year of life $(35.7 \%$ of cases) and decrease subsequently during the following years. These data are matched with that published by Mchaile et al. ${ }^{(16)}$, who found that the overall prevalence of rotavirus in this study was $26.4 \%(73 / 277)$ and it was $29 / 73(39.7 \%)$ in infants aged less than 12 months, $34.2 \%$ (25/73) in children aged 13-24 months and $21.9 \%$ (16/73) among children older than 24 months.

We found that, there was significant difference between rotavirus positive and negative cases in Vesikari score of severity, duration of hospital stay and weight of patients, which was in agreement with Bass $\boldsymbol{e t}$ al. ${ }^{(18)}$ But there was no significant difference regarding dehydration and this was in concordance with study reported by Paul $\boldsymbol{e t}$ al. ${ }^{(19)}$ and in agreement with Karyana et al. (20) who reported that clinical manifestations of rotavirus were more severe than those of other causes of viral gastroenteritis and also in agreement with Hegazi et al. ${ }^{(14)}$ who found marked significant difference regarding the G.E. severity between positive and negative rotavirus cases.

Our study revealed that $76.4 \%$ of the studied group were under weight and $87.1 \%$ of them had severe dehydration while Sudarmo et al. ${ }^{(21)}$ reported that $56.9 \%$ had normal weight. This may be due to the effect of dehydration on the body weight and partially due to the case selection as our cases were those who needed hospitalization.

Regarding the genotyping of VP7 in the present study, the only detected was G3 genotype and represented $12.5 \%$ of the studied group. This is in agreement with Magzoub et al. ${ }^{(22)}$ who found that only G1 $(83.3 \%)$ and G9 (16.7\%) were detected in his population and it was in disagreement with Tate $\boldsymbol{e t} \boldsymbol{a l}$. ${ }^{(23)}$ who reported that $53 \%$ had G3 strains and Walker $\boldsymbol{e t}$ al. ${ }^{(24)}$ showed that G1 and G9 genotypes were the most prevalent. This difference may be due to different laboratory protocols and resources. And it is also in disagreement with Ahmed $\boldsymbol{e t}$ al. ${ }^{(13)}$ who reported that the most common was G2, G1 and G9 respectively.
We also found that $33.6 \%$ of the studied group had P8 strain. This was in agreement with Trimis et al. (25) who reported that $24.7 \%$ had P8 and also in agreement with Magzoub et al. ${ }^{(22)}$ who also detected only P8 in one case of his 121 cohort and our data also were in agreement with Bulut et al. ${ }^{(15)}$ who found P8 as the most prevalent type. While Soenarto et al. (26) showed that $55.6 \%$ had P6 strain and $17.5 \%$ had P8 strain and Ahmed et al. ${ }^{(13)}$ were able to detect only $58 \%$ of his population while $42 \%$ were nontypable for $\mathrm{P}$ strains.

In the present study $53.9 \%$ of the studied group were nontypable $\mathrm{G}$ nontypable $\mathrm{P}$, which was in disagreement with Sprengers $\boldsymbol{e t}$ al. ${ }^{(27)}$ who reported that only $1.6 \%$ of his cases were nontypable.

The present study showed that there was statistically significant difference between G3 strain and nontypable $G$ strains regarding dehydration and Vesikari score of G.E. severity with more severe in nontypable G, which was in agreement with Sudarmo et al. (21) and Lopman et al. (28) who reported a significant difference in several analysis.

There was statistically significant difference between P8 and nontypable G strain in Vesikari score of severity, vomiting duration, number of vomitus, degree of dehydration and weight but there was no significant difference in other factors, which was in agreement with Rudan et al. ${ }^{(29)}$ and Neves et al. ${ }^{(30)}$, while Clemens et al. ${ }^{(31)}$ reported that $\mathrm{P}$ strain and nontypable $\mathrm{G}$ showed no significant difference in total Vesikari score of severity ${ }^{(29-31)}$.

\section{Conclusion:}

- Rotavirus still represent high percentage of hospitalized cases of G.E. in Zagazig University Hospital.

- Most cases of severe G.E and complicated cases are related to rotavirus infection

- There is significant difference in severity and complications between positive and negative rota cases.

- Rotavirus G.E represents hard financial burden in our community.

\section{REFERENCES}

1. Payne D, Vinjé J, Szilagyi $P$ et al. (2013): Norovirus and medically attended gastroenteritis in US children. New England Journal of Medicine, 368(12):1121-1130.

2. Khoury H, Ogilvie I, El Khoury A et al. (2011): Burden of rotavirus gastroenteritis in the Middle Eastern and North African pediatric population. BMC Infectious Diseases, 11(1):9-12.

3. Delogu R, Presti A, Ruggeri F et al. (2013): Full-genome characterization of a G8P [8] rotavirus that emerged among children with diarrhea in Croatia in 2006. Journal of Clinical Microbiology, 51(5):1583-1588.

4. Ibrahim S, El-Bialy A, Mohammed M et al. (2015): Detection of Rotavirus in children with acute gastroenteritis in 
Zagazig University Hospitals in Egypt. Electronic Physician, 7(5):1227-31.

5. Bhan A, Green S (2011): Balancing safety, efficacy and cost: Improving rotavirus vaccine adoption in low-and middleincome countries. Journal of Global Health, 1(2):148-153.

6. Malek M, Teleb N, Abu-Elyazeed $R$ et al. (2010): The epidemiology of rotavirus diarrhea in countries in the Eastern Mediterranean Region. Journal of Infectious Diseases, 202(1):12-22.

7. Wang Y, Kobayashi N, Zhou D et al. (2007): Molecular epidemiologic analysis of group A rotaviruses in adults and children with diarrhea in Wuhan city, China, 20002006. Archives of Virology, 152(4):669-685.

8. Nakawesi J, Wobudeya E, Ndeezi G et al. (2010): Prevalence and factors associated with rotavirus infection among children admitted with acute diarrhea in Uganda. BMC Pediatrics, 10(1):69-72.

9. Donato C, Ch'ng L, Boniface K et al. (2012): Identification of strains of RotaTeq rotavirus vaccine in infants with gastroenteritis following routine vaccination. The Journal of Infectious Diseases, 206(3):377-383.

10. Ruuska T, Vesikari T (1990): Rotavirus disease in Finnish children: use of numerical scores for clinical severity of diarrhoeal episodes. Scand J Infect Dis., 22:259-267.

11. WHO (2009): Manual of rotavirus detection and characterization methods. Ordering code: WHO/IVB/08.17 Printed: October 2009. Available at: www.who.int/vaccinesdocuments/

12. Trojnar E, Sachsenröder J, Twardziok S et al. (2013): Identification of an avian group A rotavirus containing a novel VP4 gene with a close relationship to those of mammalian rotaviruses. Journal of General Virology, 94(1):136-142.

13. Ahmed K, Batuwanthudawe $\mathrm{R}$, Chandrasena $\mathbf{T}$ et al. (2010): Rotavirus infections with multiple emerging genotypes in Sri Lanka. Archives of Virology, 155(1):71-75.

14. Hegazi M, Sayed M, Sindi H et al. (2017): Is rotavirus still a major cause for diarrheal illness in hospitalized pediatric patients after rotavirus vaccine introduction in the Saudi national immunization program? Medicine, 96(15):6574-78.

15. Bulut Y, Yenişehirli G, Durmaz R. (2017): Molecular epidemiology of rotavirus strains in under five children. The Indian Journal of Pediatrics, 17: 1-5.

16. Mchaile D, Philemon R, Kabika S et al. (2017): Prevalence and genotypes of Rotavirus among children under 5 years presenting with diarrhoea in Moshi, Tanzania: a hospital based cross sectional study. BMC Research Notes, 10(1):542-48.

17. Burton A, Tate J, Boschi-Pinto C et al. (2012): 2008 estimate of worldwide rotavirus-associated mortality in children younger than 5 years before the introduction of universal rotavirus vaccination programmes: a systematic review and meta-analysis. The Lancet Infectious Diseases, 12(2):136-141.
18. Bass D (2011): Rotaviruses, caliciviruses, and astroviruses. Nelson Textbook of Pediatrics. 19th ed. Philadelphia, Pa: Saunders Elsevier. Pp. 142.

19. Paul S, Ghosh S, Hossain $M$ et al. (2011): Full genomic analyses of two human G2P [4] rotavirus strains detected in 2005: identification of a caprine-like VP3 gene. Journal of General Virology, 92(5):1222-1227.

20. Karyana I, Salim H, Sanjaya-Putra I et al. (2014): Risk factors of rotavirus diarrhea in hospitalized children in Sanglah Hospital, Denpasar: a prospective cohort study. BMC Gastroenterology, 14(1):54.

21. Sudarmo S, Shigemura K, Osawa K et al. (2015): Genotyping and clinical factors in pediatric diarrhea caused by rotaviruses: one-year surveillance in Surabaya, Indonesia. Gut Pathogens, 7(1):3-7.

22. Magzoub M, Bilal N, Bilal J et al. (2017): Detection and sequencing of rotavirus among Sudanese children. The Pan African Medical Journal, 28:16-21.

23. Tate J, Burton A, Boschi-Pinto C et al. (2012): 2008 estimate of worldwide rotavirus-associated mortality in children younger than 5 years before the introduction of universal rotavirus vaccination programmes: a systematic review and meta-analysis. The Lancet Infectious Diseases, 12(2):136-141.

24. Walker C, Rudan I, Liu L et al. (2013): Global burden of childhood pneumonia and diarrhoea. The Lancet, 381(9875):1405-1416.

25. Trimis G, Koukou D, Chatzichristou $P$ et al. (2015): Rotavirus gastroenteritis in a neonatal unit of a Greek tertiary hospital: clinical characteristics and genotypes. PloS one, 10(7):133-138.

26. Soenarto Y, Prasetyo D, Martiza I (2010): Surveillance of rotavirus diarrhea in Dr. Hasan Sadikin general hospital Bandung. Majalah Kedokteran Bandung, 42(4):155-160.

27. Sprengers D, Yin Y, Metselaar H et al. (2015): Rotavirus in Organ Transplantation: Drug Virus-Host Interactions. American Journal of Transplantation, 15(3):585593.

28. Lopman B, Payne D, Tate J et al. (2012): Post-licensure experience with rotavirus vaccination in high and middle income countries; 2006 to 2011. Current Opinion in Virology, 2(4):434-442.

29. Rudan I, Nair H, Marušić A et al. (2013): Reducing mortality from childhood pneumonia and diarrhoea: The leading priority is also the greatest opportunity. Journal of Global Health, 3(1): 010101.

30. Neves M, Pinheiro H, Silva R et al. (2016): High prevalence of G12P [8] rotavirus strains in Rio Branco, Acre, Western Amazon, in the post-rotavirus vaccine introduction period. Journal of Medical Virology, 88(5):782-789.

31. Clemens J, Holmgren J, Kaufmann S et al. (2010): Ten years of the Global Alliance for Vaccines and Immunization: challenges and progress. Nature Immunology, 11(12):106973. 